\title{
Initial Tract Formation in the Mouse Brain
}

\author{
Stephen S. Easter, Jr., ${ }^{1,2}$ Linda S. Ross, ${ }^{1,3}$ and Anthony Frankfurter ${ }^{4}$ \\ 'Department of Biology, University of Michigan, Ann Arbor, Michigan 48109-1048, 2INSERM U. 106, Hôpital de la \\ Salpêtrière, Paris, France 75013, ${ }^{3}$ Department of Biological Sciences, Ohio University, Athens, Ohio, 45701, and \\ ${ }^{4}$ Department of Biology and Neuroscience Program, University of Virginia, Charlottesville, Virginia 22901
}

\begin{abstract}
Mouse embryos from embryonic days 8.5-10.5 (E8.5-E10.5) were fixed and labeled with an antibody to neuron-specific class III $\beta$-tubulin (Moody et al., 1987; Lee et al., 1990a,b) to reveal the first neurons, axons, and tracts in the brain. They were studied in whole-mounts and in light microscopic sections. Some conclusions were checked by labeling tracts in older embryos (E11.5 and E12.5) with the lipophilic dye 1,1'dioctadecyl-3,3,3',3'-tetramethylindocarbocyanine.
\end{abstract}

The first immunoreactive cells appeared at E8.5, prior to neural tube closure, in the neural plate immediately caudal to the optic vesicle. Cells along the dorsal midline of the mesencephalon issued the first axons, on E9.0; the cells were the mesencephalic nucleus of the trigeminal nerve, and the axons formed its descending tract. The tract reached the level of the trigeminal ganglion by $\mathrm{E} 10.0$ but did not enter the ganglion until after E12.5. On E9.5, the number of labeled cells and axons in the alar plate of the presumptive diencephalon and mesencephalon had increased substantially, and many of the rostral ones coursed into the basal plate to enter longitudinal tracts there. Two tracts originated from cells in the basal plate: the tract of the postoptic commissure (from the base of the optic stalk to the level of the cephalic flexure) and the medial longitudinal fasciculus (from the level of the cephalic flexure caudally through the mid and hindbrains). By E10.0, a small mammillotegmental tract paralleled the tract of the postoptic commissure, but immunolabeling was so widespread that discrete tracts were impossible to discern in the presumptive diencephalon and mesencephalon. The more rostral regions remained lightly labeled. In the cerebral vesicle, the presumptive cerebral cortex, the first immunoreactive cells appeared at E10.0; they had multiple processes oriented parallel to the pia, and were identified as the Cajal-Retzius cells. By E 10.5, no tracts had formed in the cerebral vesicle.

All the tracts formed by $\mathbf{E} \mathbf{1 0 . 0}$ were superficial, in the subpial lamina. Those that can be identified in the adult brain are very deep structures.

\footnotetext{
Received May 21, 1992; revised July 20, 1992; accepted July 22, 1992

We thank Dr. Constantino Sotelo and the staff of the INSERM U. 106 for their hospitality and help while S.S.E. was a guest there; Drs. Sotelo, R. M. AlvaradoMallart, S. A. Bayer, M. Edwards, S. Martinez, S. A. Moody, L. Puelles, K. S. O'Shea, and M. Wassef for technical help and useful discussions; and Ms. C. Malinoski for doing the histology and the photography. This work was supported by research grants from the NIH to S.S.E. (EY-00168) and to A.F. (NS-21142), and by INSERM. L.S.R. was supported by traineeships from NIH (HD-07274 and EY-07022)

Correspondence should be addressed to Professor Stephen S. Easter, Jr., Department of Biology, Natural Science Building, University of Michigan, Ann Arbor, MI 48109-1048.

Copyright (C) 1993 Society for Neuroscience $0270-6474 / 93 / 130285-15 \$ 05.00 / 0$
}

These results are compared with previous descriptions of the embryonic brains of amphibians, fish, birds, and other mammals, including humans.

IKey words: embryo, mouse, chick, tract formation, CNS development, class III $\beta$-tubulin, medial longitudinal fasciculus, trigeminal, tract of the postoptic commissure]

The first axogenesis and tract formation in the CNS are obviously important events, as they begin the complex task of forming the network on which neural function depends. Our observations on anamniotic vertebrates have led us to argue that the first set of tracts serve as a "scaffold" on which most later tracts form (Easter and Taylor, 1989; Wilson et al., 1990), and the present article is, in part, an attempt to assess the generality of those observations. But the interest in early tract formation has a much longer history; from the late nineteenth century through the 1940s, numerous reports attempted to describe this process in vertebrate embryos, with Herrick, Tello, and Windle playing particularly important roles. They used all the anatomical techniques available at that time (especially silver stains), and agreed that the basal plate developed earlier than the alar, and that the medial longitudinal fasciculus ( $\mathrm{mlf}$ ) was the first tract to appear in the presumptive fore- and midbrain, at about the same time as rhombomeric clusters of differentiated cells in the hindbrain (e.g., Angulo y Gonzalez, 1939; Rhines and Windle, 1941). The modern reader marvels at how much they could see, given their rather crude methods (by modern standards), but their conclusions are so fundamental that they warrant being checked with more powerful methods.

Axon tracers and antibodies against neuron-specific molecules are well suited to this task. They, and a battery of other powerful techniques, have been applied in recent years to the study of early embryos, and the most complete descriptions have been of the invertebrates, particularly insect (Thomas et al., 1984), leech (Weisblat, 1988), and nematode (Sulston et al., 1983). The vertebrates have also been studied in this context, particularly the anamniotes (amphibia: Roberts and Clarke, 1982; fish: Eisen et al., 1986; Kuwada, 1986; Trevarrow et al., 1990; Wilson et al., 1990). Surprisingly, early tract formation in the amniotic vertebrates, birds and mammals, has been studied relatively little (and the reptiles not at all). Most studies of amniotic embryos have concentrated on relatively late events, such as the formation of the visual system, the cerebellum, and the cerebral cortex. The few exceptions to this generalization have dealt with the hindbrain of chick (Lumsden and Keynes, 1989; Glover and Petursdottir, 1991) and mouse (Letourneau et al., 1988), the spinal cord (Dodd et al., 1988), and the trigeminal system (Covell and Noden, 1989; Stainier and Gilbert, 1989, 1990, 1991). The onset of the expression of particular molecules associated 

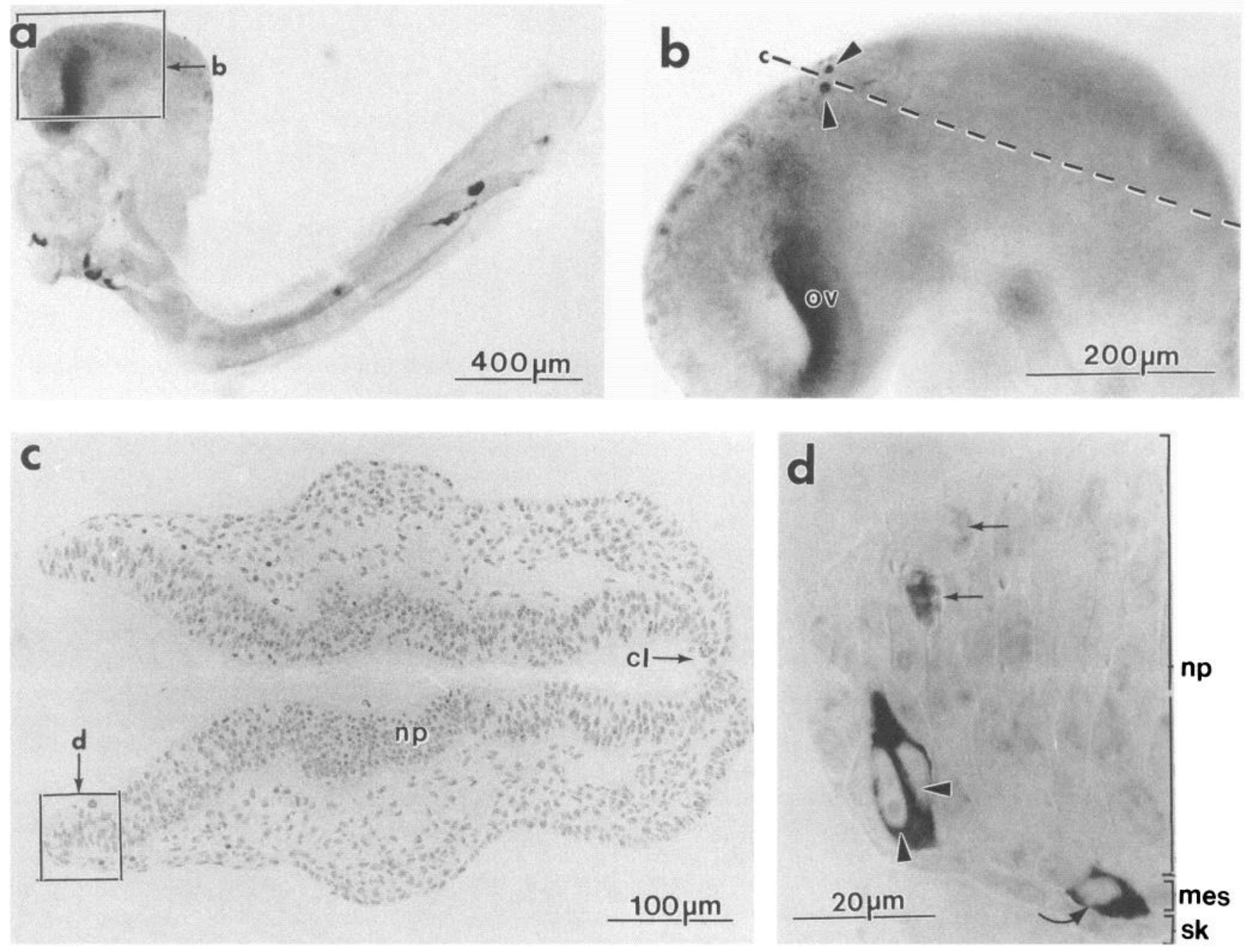

Figure 1. Embryos, E8.5. $a$, Whole-mount, seen from the left side. The box labeled $b$ indicates the field seen in $b . b$, Two labeled cells are indicated by the arrowheads. The optic vesicle (ov) is beginning to form. The broken line labeled $c$ indicates the plane of the section shown in $c$. $c$, A different embryo than $b$, Toluidine blue-stained section through the presumptive mid- and hindbrain, with rostral to the left and caudal to the right. The neural plate $(n p)$ is easily distinguished from the other tissue layers. The neural tube is open rostrally, closed $(c l)$ caudally. The $b o x$ labeled $d$ indicates the field seen in $d$. $d$, Different embryo than $c$. The neural ridge includes the thickened neural plate ( $n p)$, the mesenchyme (mes), and the skin $(s k)$. Labeled cells lie in the neural plate (arrowheads) and the mesenchyme (curved arrow). The straight arrows indicate two mitotic cells that are densely stained by the toluidine blue, not by the antibody.

with axons has been studied in rodents (e.g., neurofilaments: Cochard and Paulin, 1984; NILE glycoprotein: Stallcup et al., 1985), but these studies have not focused on particular tracts.

In this article, we report on embryonic mice, with an emphasis on the presumptive fore- and midbrain. We have visualized the new tracts in both sections and whole-mounted brains. Although we have confirmed some of the previously published material, we find a major difference-the first tract to appear is the descending tract of the mesencephalic nucleus of the trigeminal nerve (dtmesV), a tract in the alar plate, not the basal plate.

We suggest that this method, which reveals patterns of differentiation and tract formation, should be useful for future studies of early development in mutant mice.

A preliminary account of some of this work has appeared in abstract form (Ross and Easter, 1991).

\section{Materials and Methods}

Pregnant albino mice (Swiss strain) were obtained commercially from Iffa-Credo, Lyon, France. Mating occurred between 6 P.M. and 8 A.M. on the one night that males and receptive females were left together; for purposes of assigning an age to the embryos, conception was assumed to have occurred at midnight, so the embryos at noon the next day were taken as embryonic day 0.5 (E0.5). The dams were killed by cervical dislocation at about noon or midnight, and the ages of the embryos ranged from E8.5 to E12.5, in half-day intervals. The embryos were dissected out individually in buffered $2 \%$ paraformaldehyde, and fixed for $2-4 \mathrm{hr}$. The time from the death of the dam to the last of the embryos entering fixative never exceeded $20 \mathrm{~min}$. Litters that differed by a halfday's gestation produced clearly different "average" embryos, but the least developed in one litter were often indistinguishable from the most developed in the $0.5 \mathrm{~d}$ younger litter. We did not count somites, nor did we attempt to stage the embryos. When we give characteristics of a particular age, it should be understood that these refer to, and most of our illustrations show, "average" embryos.

Following fixation, embryos were transferred to buffer. Most were cut along the dorsal midline to enhance penetration by reagents.

Immunocytochemistry. In preliminary experiments, we tried a variety of primary antibodies, and found that the $\mathrm{TuJ} 1$ antibody to neuronspecific class III $\beta$-tubulin (Moody et al., 1987; Lee et al., 1990a,b) labeled cells and axons best. All the immunocytochemical results presented here were obtained with TuJ1. We assume tentatively that all central neuronal somata and axons are labeled by this antibody. (This 

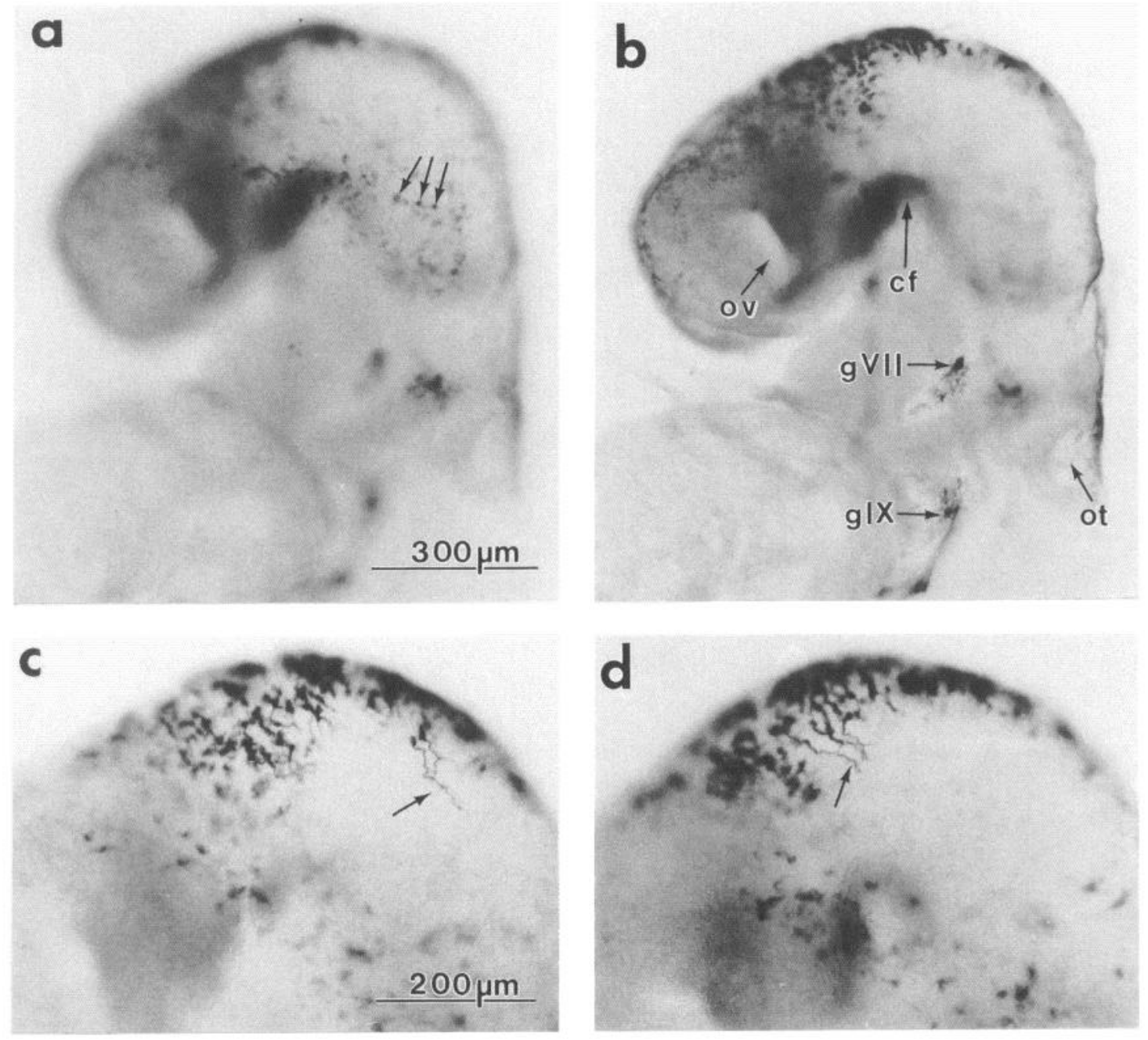

Figure 2. Embryos, E9.0. All panels show whole-mounts viewed from the left. $a$, The focal plane is superficial to the neural tube, and many labeled cells (arrows), in either the mesenchyme or skin, are evident. $b$, Same embryo, with the focal plane deeper, on the neural tube. The labeled cells are more numerous than at E8.5, and form a wedge, its broad base along the dorsal midline, its apex pointed toward the cephalic flexure ( $c f$ ). The optic vesicle $(o v)$, ganglion of cranial nerve VII $(g V I I)$, ganglion of cranial nerve IX $(g I X)$, and otocyst (ot) are evident. $c$ and $d$, Slightly more highly magnified views of the first axons on the wall of the mesencephalon in different embryos. A large number of cells have axons, the longest of which may be on caudal cells (arrow in c) or rostral ones (arrow in $d$ ). The scales in $a$ and $c$ also apply to $b$ and $d$, respectively.

point is taken up again in the Discussion.) After fixation, the embryos were permeabilized by putting them in distilled water and then $(5 \mathrm{~min}$ at each stop) in an ascending series of ethyl alcohols $(30 \%, 50 \%, 70 \%$, $90 \%, 100 \%)$ to xylene, and then returned through the same set of concentrations back to distilled water. Next, they were put in $-20^{\circ} \mathrm{C}$ acetone for $10 \mathrm{~min}$ before returning to distilled water.

Nonspecific reactions were blocked by incubation for $60 \mathrm{~min}$ in a phosphate-buffered solution of $0.2 \%$ gelatin, $0.1 \%$ sodium azide, $0.25 \%$ Triton X-100, and $0.1 \mathrm{~m}$ lysine. After rinsing, the tissue was incubated overnight in the primary antibody (1:500 dilution), rinsed, incubated in a goat anti-mouse secondary antibody for $1 \mathrm{hr}$, rinsed again, and incubated $1 \mathrm{hr}$ in a peroxidase-conjugated tertiary antibody. All incubations and rinses were carried out at room temperature, on a shaker table. The HRP reaction was carried out with diaminobenzidine and hydrogen peroxide.

Most of the reacted embryos were bisected sagittally, dehydrated to absolute alcohol, cleared in xylene, and whole-mounted in Eukitt between two coverslips, using a variable number of coverslip fragments as spacers. Others were left intact, embedded in glycol methacrylate, sectioned (3-15 $\mu \mathrm{m})$, and stained with toluidine blue.

DiI labeling. Fixed embryos were labeled by applying small fragments of the lipophilic dye 1,1'-dioctadecyl-3,3,3',3'-tetramethylindocarbocyanine (DiI; Molecular Probes; Honig and Hume, 1986; Godement et al., 1987) to the brain or the trigeminal ganglion (see below for details of the sites). The DiI had been dissolved in dimethylformamide, which was allowed to evaporate, leaving fragments $20-100 \mu \mathrm{m}$ in diameter. After the fragment was inserted, the embryo was stored in fixative, at $38.6^{\circ} \mathrm{C}$, in the dark, and examined periodically in a fluorescence microscope to monitor the advance of the label. At the elevated temperature, labeling progressed rapidly, and showed no significant change after about $4 \mathrm{~d}$. The embryos were dissected, bisected sagittally, and mounted in $50 \%$ fixative, $50 \%$ glycerine.

Microscopy. The preparations (whole-mounts and sections) were examined in both transmitted light and fluorescence epiillumination, and photographed or drawn through a camera lucida.

\section{Results}

E8.5. The neural tube had closed caudally, but the rostral neural folds were in a wing-like position, beginning their dorsad swing toward closure (Fig. 1c). The presumptive brain, viewed laterally, was shaped like the letter $\mathrm{N}$, with rostral, middle, and caudal thirds (Fig. 1a). Rostrally, two bilaterally symmetrical evaginations, the presumptive optic vesicles (Svoboda and O'Shea, 1987), were evident. The middle third, roughly the presumptive midbrain, was bent ventrally at the transverse ce- 

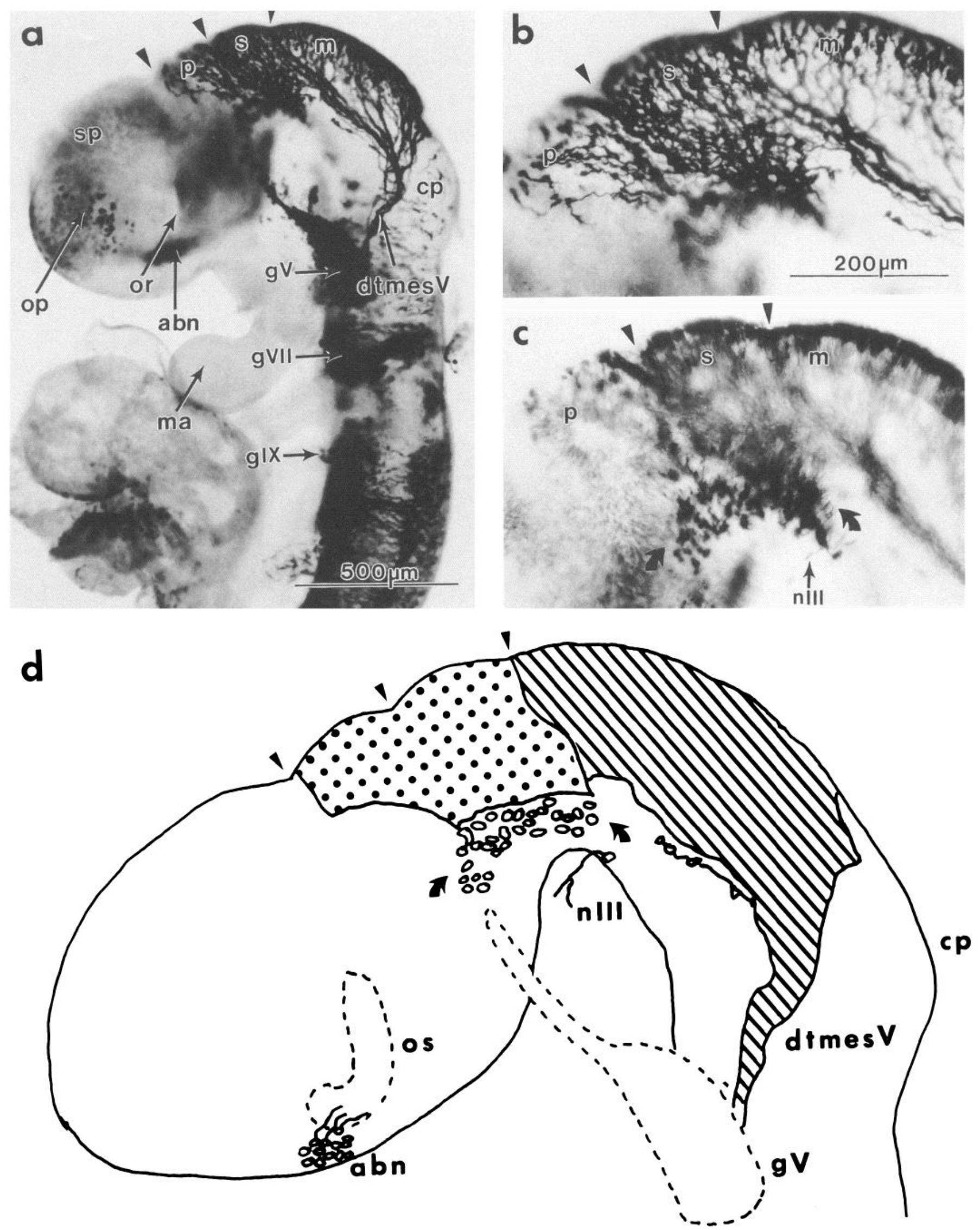

Figure 3. Embryo, E9.5. All panels show a lateral view, with anterior to the left, of the same whole-mount, $a$ at low magnification, $b$ and $c$ at slightly higher magnification and at different focal planes; $d$ is an interpretive camera lucida drawing. $a$, The focal plane is relatively superficial. 

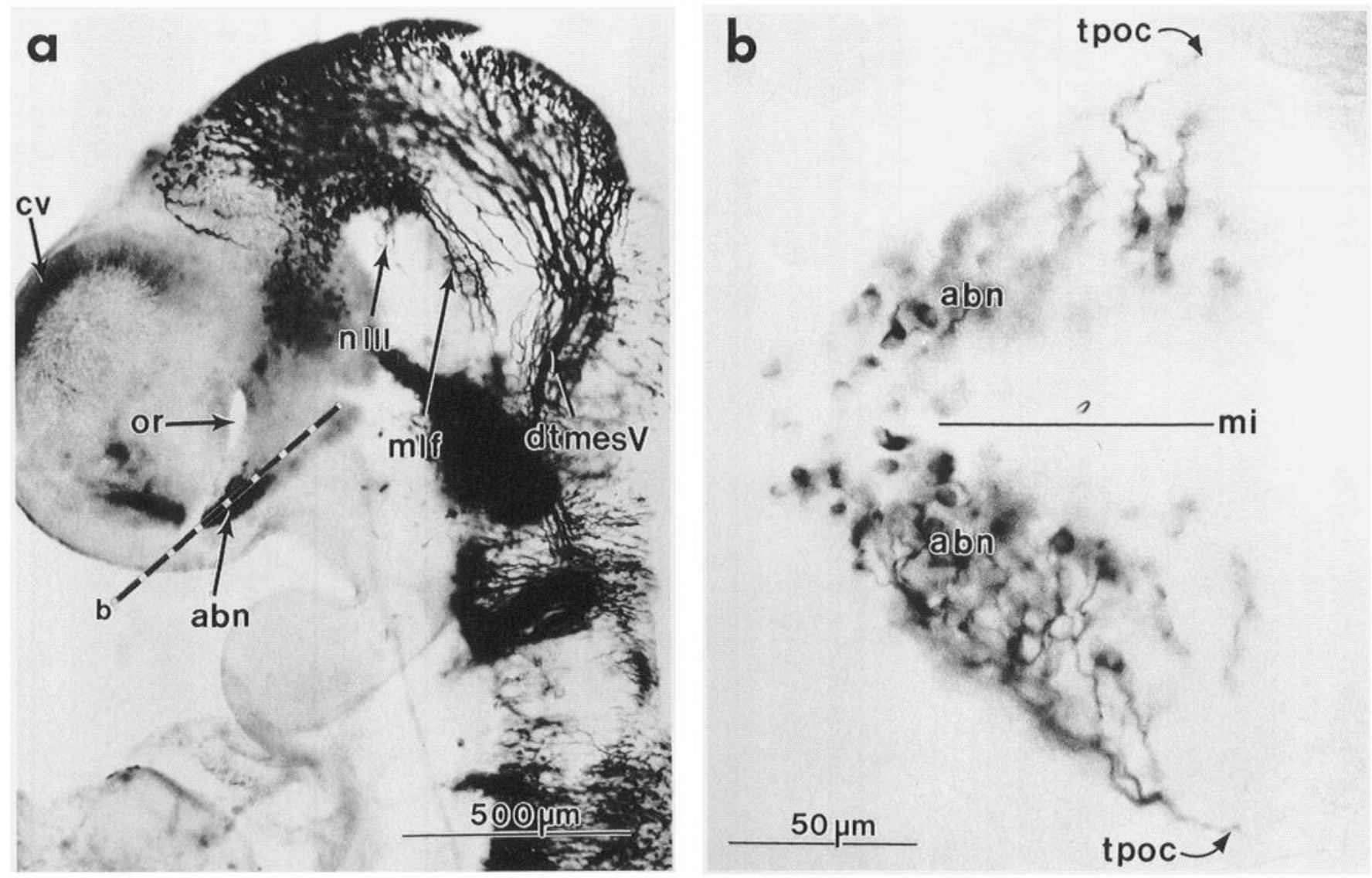

Figure 4. Embryos, E9.5. a, Lateral view of a whole-mount, with anterior to the left. This is somewhat more advanced than the one shown in Figure 3. The same structures noted in Figure 3 are evident, as well as the medial longitudinal fasciculus $(\mathrm{m} / \mathrm{f})$ and the cerebral vesicle $(\mathrm{cv})$. The line labeled $b$ indicates the plane of section of $b . b$, A section through a different embryo, with rostral to the left, and the midline shown by mi. The axons from the cells of the anterobasal nuclei $(a b n)$ grow caudally, forming the tract of the postoptic commissure (tpoc); the commissure has not yet formed. Compare with Figure $8 f$, another view of the abn.

phalic flexure where it formed an acute angle with the rostral third. The caudal third was bent dorsally with respect to the middle, thus throwing the embryo into a scorpion-like posture.

The first labeled cells were near the neural folds. Most lay in the neural plate, but a few were in the mesenchyme between neural plate and skin. This location suggests that they are neural crest cells, and the neural crest is generated at this time (Chan and Tam, 1988), but in chick, crest cells are not labeled by this antibody (Moody et al., 1987; Lee et al., 1990a), so their origin remains obscure. The labeled cells in the neural plate were in the presumptive alar plate, at the level of the caudal border of the optic evagination and near the junction of the first twothirds (Fig. $1 b-d$ ). Apparently the $\beta$-tubulin immunoreactivity appeared around E8.5, because in the 24 half-brains of that age that were examined (from two litters), 14 had no labeled cells, and the others had 2-11 each, with a median of 4 . The labeled cells contained reaction product in the cytoplasm only, not in the nucleus. Those in the neural plate were fusiform, with no processes other than those to the end-feet. Reaction product was never seen in processes contacting the presumptive ventricle. This may imply that these immunoreactive cells lacked apical processes, or that the apical processes were present but not labeled; neither of these alternatives can be excluded. They may be neural crest cells about to exit the plate, or they may be the first neurons of the CNS.

E9.0. Most of the embryos had lost the dorsal flexure between middle and caudal thirds, and assumed a more conventionally embryonic shape, concave ventrally along the entire longitudinal axis (Fig. 2).

In the periphery, labeled cells, presumably neural crest or

The four neuromeres, the mesencephalon $(m)$, synencephalon $(s)$, parencephalon $(p)$, and secondary prosencephalon $(s p)$, are evident as bulges whose dorsal boundaries are marked by arrowheads. The optic recess (or), the anterobasal nucleus $(a b n)$, the mandibular arch ( $m a)$, and the trigeminal ganglion $(g V)$ are now evident; the facial nerve ganglion $(g V I I)$ is larger; the olfactory placode $(o p)$ has labeled cells; and the axons from the dorsal mesencephalon have now coalesced into a tract, the descending tract of the mesencephalic nucleus of the trigeminal nerve $(d t m e s V)$, that courses ventral to the cerebellar plate $(c p)$ and extends to the trigeminal ganglion. $g I X$, ganglion of cranial nerve IX. $b$, A detail of the three neuromeres $(p, s$, and $m)$ that contain labeled axons. Although the fascicles are tangled everywhere, those in the synencephalon and parencephalon have a more ventral bias than those in the mesencephalon, which course more caudally. $c$, A deeper plane of focus in the same field as in $b$. The labeled cells in the basal plate are indicated by curved arrows. The first axon of the oculomotor nerve $(n I I I)$ has emerged. The scale in $b$ also applies to $c$. $d$, A camera lucida drawing of part of this same embryo, showing the axon-covered parts of the parencephalon and synencephalon in dots, and that of the mesencephalon in diagonal lines. The first axons from the anterobasal nucleus $(a b n)$ have begun to grow around the optic stalk (os). 

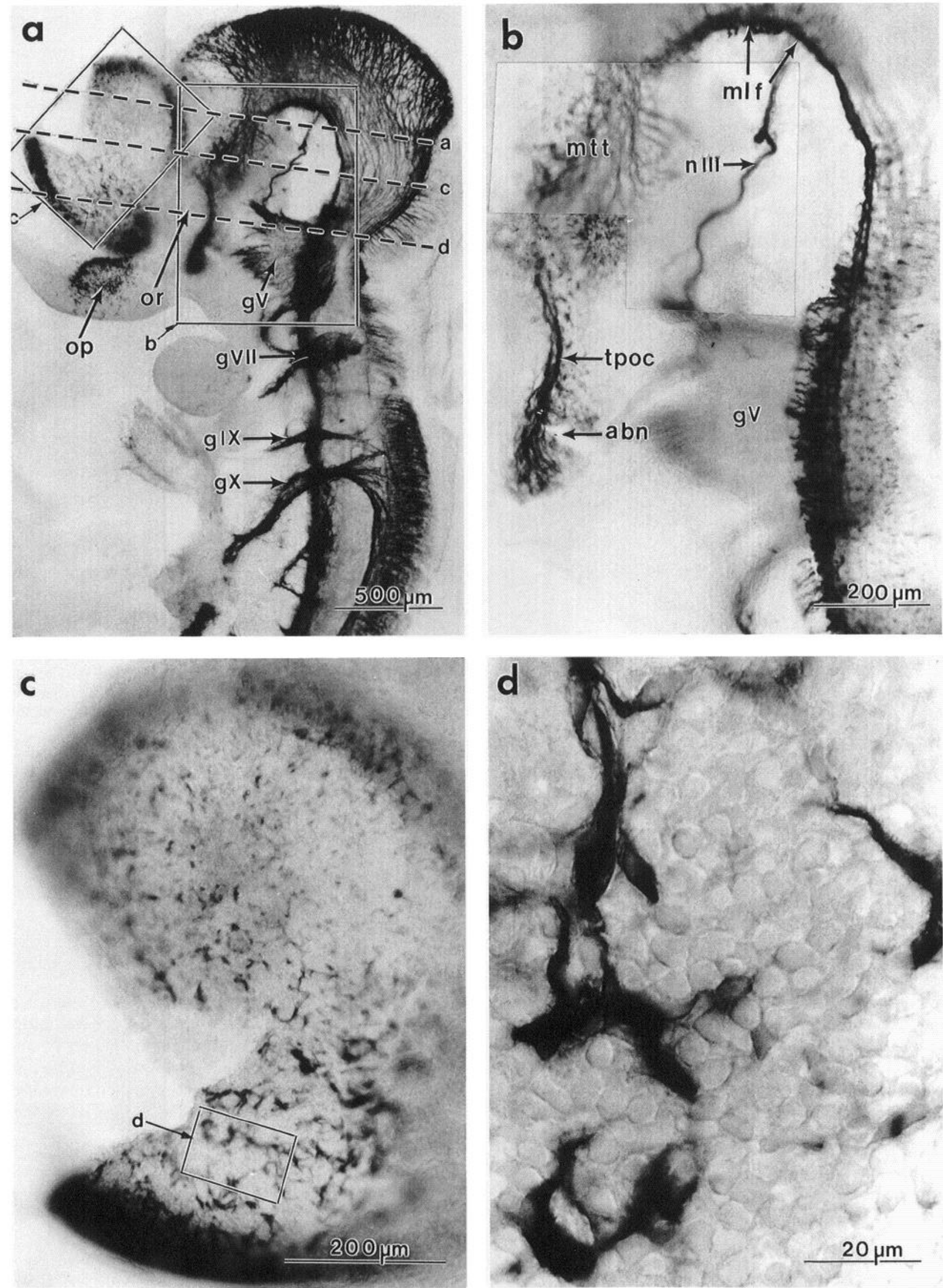

Figure 5. Embryos, E10.0. All panels are from the same embryo. $a$, A whole-mount viewed from the left. The cerebral vesicle (enclosed in the box labeled $c$ ) has been flattened and a break has appeared on its dorsorostral quadrant. The olfactory placode (op) has artifactually pulled away from the cerebral vesicle (compare Fig. $8 d$ ). The optic recess (or) and the ganglia of cranial nerves V, VII, IX, and X $(g V, g V I I, g I X$, and $g X)$ are 
placodal, were diffusely spread around the level of the cephalic flexure (Fig. $2 a$ ) and others were concentrated in the presumptive ganglia of cranial nerves VII and IX (Fig. $2 b$ ).

In the CNS, the cephalic flexure was still prominent, the optic evaginations had enlarged slightly, and the numbers of labeled cells were markedly greater than at E8.5. The alar group extended along the dorsal midline of the presumptive diencephalon and mesencephalon, including the region with the cells labeled at E8.5. Rostrally, the labeled cells formed a wedge with its base along the brain's dorsal surface and its apex pointing ventrally toward the cephalic flexure but not reaching the ventral surface (Fig. $2 c, d$ ). The dorsorostral quadrant of the otic placode contained a few lightly labeled cells. Three basal clusters of labeled cells (rhombomeres) appeared in the rhombencephalon, and still more caudally, labeled cells lay in the basal plate of the remainder of the hindbrain and the anterior spinal cord, their density decreasing steadily caudally (not illustrated). Thus, in the CNS, the first immunoreactive cells appeared in the alar plate, and were accompanied within about $0.5 \mathrm{~d}$ by a widely distributed set of labeled clusters in the basal plate. The first axons in the CNS appeared at E9.0, originating from the cells in the mesencephalic alar plate (Fig. 2).

Over the next day, the brain became too complex to be described as we have done up to this point, by considering the development of the CNS as a whole. Accordingly, the remainder of Results is divided into sections organized around the development of tracts and other structures. By way of introduction, at E9.5, the labeled cells and axons were much more numerous, as Figures 3 and 4 show. In the alar plate, labeled cells and their axons covered three neuromeres (the mesencephalon, the synencephalon, and the parencephalon; Puelles ct al., 1987) and the cerebellar plate. In the basal plate, they appeared in two patches, one at the base of the optic stalk, the other at the level of the cephalic flexure. By E10.0, many of the early tracts were no longer resolvable in immunocytochemical whole-mounts (Fig. 5 ) and details about circuitry were obtained with other means: Dil labeling (Fig. 6, 7) and sectioning (Fig. 8).

The dtmes $V$. At E9.0, most labeled cells in the alar plate had axons, and virtually all were directed away from the midline, thus producing a clear dorsomedial strip free of axons. Most axons near the midline joined with their neighbors in laterally directed fascicles. The longest axons usually arose from the more lateral cells (Fig. 2c,d). Although they frequently fasciculated with one another, the fascicles advanced broadly and independently of one another across the mesencephalon, directed ventrally and caudally. They were all on the surface of the brain, immediately deep to the pia.

By E9.5, the axons on the mesencephalon collected together to form a longitudinal tract on the dorsolateral surface of the brain (Fig. 3). This is dtmesV, and the cells of origin constitute the mesencephalic nucleus of the trigeminal nerve (nmesV). These identifications are based on the observations (Taber Pierce, 1973; McConnell, 1981) that the earliest neurons born in the dorsal mesencephalon of the mouse were in nmesV early on E9. Tectal neurogenesis, by comparison, began on E10 (Taber Pierce, 1973).

The exact boundaries of nmesV could not be discerned with a general axonal label such as ours; in particular, cells rostral to the mesencephalon almost certainly contributed axons to dtmes $\mathrm{V}$, as the tangled axonal network extended across the boundary between mesencephalon and synencephalon. The textures and directions of the axonal tangles were quite different on either side of the border, as Figure $3 b$ illustrates. The fascicles in the mesencephalon were coarser, and had a decided caudal bias, which carried them into the dtmesV. Those in the synencephalon were finer and more tightly packed, and tended to course ventrally; they are probably the pioneers of the tract of the posterior commissure and the fasciculus retroflexus, which Edwards et al. (1989) have described in slightly older embryos.

Caudal to the mesencephalon, the dtmesV narrowed, veered laterally to course around the cerebellar plate, which contained few labeled cells at this time, and reached the level of the trigeminal ganglion. The dtmesV was several fascicles wide, and was still clearly separate from the basal plate, which also contained axons in relatively advanced embryos of this stage (Fig. $4 a$; compare to Fig. $3 a$ ). By E10.0, the dtmesV had broadened so much that the separation between it and the mlf was obliterated (Fig. 5a). The axons of the dtmesV lay in the subpial lamina, immediately superficial to their somata (Fig. 8e).

Although many labeled axons passed between the ganglion and the tract, it was impossible to discern if any of them had originated from somata in the dorsal mesencephalon. To address this question, the carbocyanine dye Dil was applied directly to the dorsomedial mesencephalic surface, to label the descending axons anterogradely; or to the trigeminal ganglion, to label the central somata contributing axons to the ganglion. The anterograde labeling was carried out in 11 embryos ranging from E10.0 to E12.5, and one example is shown in Figure $6 a$. A portion of the dtmes $V$ is labeled quite heavily, but few of the labeled axons extended into the hindbrain beyond the level of the presumptive cerebellum, even in the oldest embryos. Many of these were tipped by growth cones, suggesting that the DiI had labeled the axons all the way to their ends, and therefore gave an accurate picture of how far they extended. In some preparations, a few were followed caudally beyond the trigeminal ganglion, but, surprisingly, no labeled axons were seen in the ganglion, even by $\mathrm{E} 12.5$.

The retrograde labeling was done in six embryos, E10.5-E12.5, and Figure $6 b-e$ shows an example. In all cases, labeled axons in the CNS extended in three directions from the trigeminal nerve root: ventromedially toward the midline, and both caudally and rostrally on the ipsilateral side. The caudally directed ones were anterogradely labeled, as the longest of them ended in growth cones (Fig. $6 d$ ). The rostral axons were retrogradely labeled, as they led to cell bodies in the rostral hindbrain (Fig. $6 c$ ); they may be either the motor nucleus of the trigeminal nerve

shown. The boxes labeled $b$ and $c$ show the fields enlarged in $b$ and $c$. The lines labeled $a, c$, and $d$ give the planes of sections of Figure $8, a, c$, and $d$, respectively. $b$, An enlarged view of the region of the cephalic flexure. The anterobasal nucleus (abn) sends axons caudally (compare Fig. $4 b$ ) past the mammillary body from which the mammillotegmental tract $(m t t)$ emerges. The medial longitudinal fasciculus $(m l f)$ originates rostral to the root of the oculomotor nerve $(n I I I)$ and extends caudally past the level of the trigeminal ganglion $(\mathrm{gV})$. $c$, An enlarged view of the cerebral vesicle. All the labeled cells are flattened parallel to the pia. They are most numerous in the lower (rostroventral) region. The $h o x$ labeled $d$ gives the region of $d . d$, The labeled Cajal-Retzius cells can be distinguished from their unlabeled neighbors. No labeled processes from cells extrinsic to the vesicle are seen. 



Figure 6. Embryos, DiI labeled. $a$, E12.5 whole-mount viewed from the side, with rostral to the left. The DiI was applied to the dorsal midline of the mesencephalon $\left(^{*}\right)$, and labeled fibers course ventrally and caudally in the descending tract of the mesencephalic nucleus of the trigeminal nerve (dtmes $V$ ), but do not enter the trigeminal ganglion (not visible in this field). $b-e$, E11.5 whole-mount viewed from the side, with rostral to the right. $b$, The boxes labeled $c-e$ show the fields in $c-e$. DiI was applied to the trigeminal ganglion $\left({ }^{*}\right)$ and labeled three sets of axons, one retrogradely $(c)$ and two anterogradely $(d$ and $e)$. $c f$, cephalic fixture; mes, mesencephalon. $c$, Retrogradely labeled somata are in the rostral midbrain, but no axons extend into the dorsal mesencephalon. $d$ and $e$, Anterogradely labeled axons, many tipped with growth cones, extend caudally almost into the spinal cord $(d)$ and ventrally toward the midline $(e)$.

or the caudalmost part of the nmesV, which is found in the adult brain near the level of the locus coeruleus (Sidman et al., 1971). No retrogradely labeled cells were found in the dorsal mesencephalon, as would be expected if the early axons from that region extended into the trigeminal ganglion. This absence cannot have resulted from a failure of the dye to diffuse that far, because the anterogradely labeled axons caudal to the ganglion were brightly labeled over a distance comparable to that between the ganglion and the dorsal mesencephalon. Thus, both labeling procedures gave results consistent with the conclusion 
that the axons originating on the dorsal mesencephalon did not extend into the ganglion by E12.5.

The mlf. The first labeled cells in the basal plate appeared on E9.5 near the cephalic flexure (Fig. $3 c, d$ ). Caudally directed axons emerged from this group to form the mlf, clearly separate from the more dorsal dtmesV (Fig. $4 a$ ). Alar plate axons originating rostral to the mesencephalon also projected ventrally past dtmesV into the basal plate, where they coursed caudally, either contralaterally, after crossing the midline, or ipsilaterally. These general routes were confirmed in DiI-labeled E11.5 embryos (data not shown), but no further details were obtained, because the large number of labeled axons prevented resolving separate tracts from these more rostral cells.

This tract is identified as the mlf because its paramedian position, ventral to the ventricle, is consistent with the position of the adult mlf (Sidman et al., 1971). Moreover, the interstitial nucleus of Cajal and the nearby nucleus of Darkshevich, both of which contribute descending axons to the mlf (Angulo y Gonzalez, 1939), contain cells with the earliest birthdates in this part of the brain (Taber Pierce, 1973).

In the most advanced E9.5 embryos, the mlf extended to the trigeminal nerve, and by E10.0, past the otic placode. The E10.5 embryos labeled so heavily in the caudal basal plate that no conclusions about the later development of the mlf could be drawn from the immunolabeled material.

The tract of the postoptic commissure (tpoc). At E9.5, cells at the base of the optic stalk were labeled and began to send out axons (Figs. 4, $8 f$ ). The early differentiation of these cells and their location suggest that they are the mouse equivalent of the rat anterobasal nucleus (abn) (Altman and Bayer, 1986). (We do not know what adult structure the abn becomes, or if it persists into adulthood.) The axons coursed caudally around the ventrocaudal border of the stalk toward the cephalic flexure. A broad strip of lightly labeled cells extended from the postoptic region to the cephalic flexure (Fig. 4a). By E10.0, axons from the abn extended caudally over this strip, past the mammillary body, from which a short tract issued (assumed to be the mammillotegmental tract; O'Rahilly et al., 1984), and reached the cephalic flexure (Fig. 5a,b).

This tract from the base of the optic stalk to the cephalic flexure is assumed to be homologous to the tract of the postoptic commissure (tpoc) that has recently been described in the embryonic Xenopus (Easter and Taylor, 1989) and zebrafish (Chitnis and Kuwada, 1990; Wilson et al., 1990; Ross et al, 1992), and to the preoptico-hypothalamic tract in humans (O'Rahilly et al, 1984). They have the same origin, in the ventral prosencephalon, and the same destination, near the site of origin of the mlf. But in the immunolabeled material, axons could not be followed individually, so it was not possible to learn if any extended into the mlf or, conversely, if any ascending axons in the mlf joined the tpoc.

These questions were examined with DiI in E11.5 embryos. DiI was applied unilaterally at the base of the optic stalk or bilaterally on the floor of the fourth ventricle, at the level of the eighth cranial nerve. The anterior application labeled axons anterogradely, and none extended beyond the cephalic flexure. No somata were labeled retrogradely by this application. The posterior application labeled axons that extended rostrally, caudally, and across the ventral midline. Both retrogradely and anterogradely labeled axons were noted in all three directions, but the important point for the particular question here is that none of the retrogradely labeled cell bodies were found in the

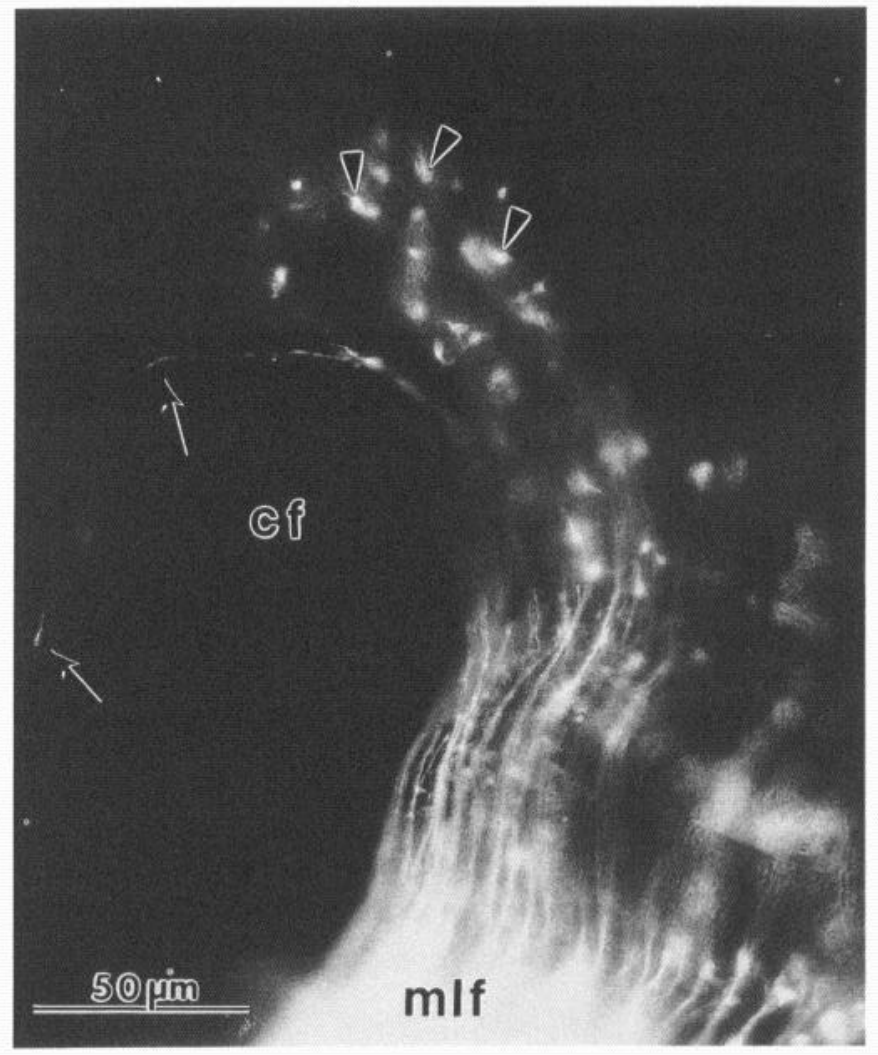

Figure 7. Embryo, E11.5. The ventral floor of the fourth ventricle was labeled with DiI at the level of the cranial nerve VII. This photomicrograph shows a lateral view of the region of the cephalic flexure $(c f)$, which contains many somata (arrowheads) retrogradely labeled through the medial longitudinal fasciculus $(\mathrm{m} / \mathrm{f})$ and a pair of anterogradely labeled growth cones (arrows) advancing along the ventral border of the brain toward the hypothalamus. No somata were labeled more rostrally.

optic stalk region; the most rostral labeled somata were at the cephalic flexure (Fig. 7). We conclude that the tpoc and the mlf did not have any axons in common by E11.5.

Early superficial axons. All of the early tracts described here formed superficially, that is, just deep to the presumptive pia, and superficial to the nuclei of the neuroepithelial cells. This was evident in the whole-mounts, and confirmed in sections such as those in Figure 8.

Olfactory placode. The first labeled cells in the olfactory placode appeared on E9.5, and steadily increased in number as the muzzle thickened (Fig. 8d). By E10.5, the first olfactory axons began to enter the anterior edge of the cerebral vesicle.

Cerebral vesicle. The first immunoreactive cells in the cerebral vesicle appeared on E10.0 (Figs. $5 a, c, d ; 8 c, d$ ), and are assumed to be the Cajal-Retzius cells (Marin-Padilla, 1972). These cells were quite superficial, and appeared flattened when viewed en face, with one to three processes extending in random directions in the plane parallel to the pial surface. They were most numerous in the anterior part of the vesicle, near the olfactory placode. By E10.5, they were considerably more numerous, but unchanged in shape, and the processes remained randomly oriented, not bundled together into presumptive tracts. Indeed, even at E10.5, when the lateral walls of the more caudal parts of the CNS were covered with labeled cells and tracts, the presumptive cortex, and most of the secondary prosencephalon caudal to it contained relatively few labeled cells. Apart from 

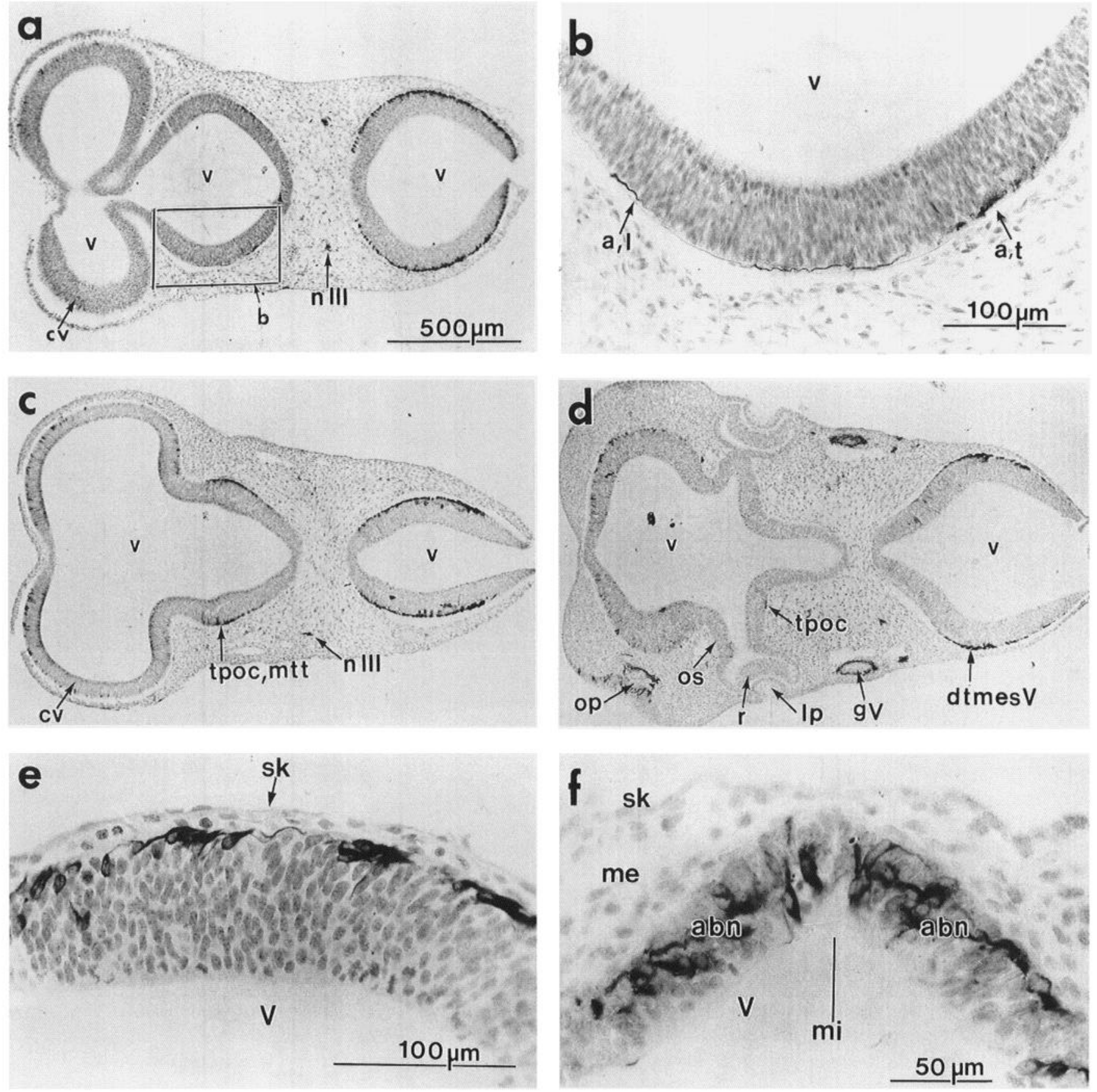

Figure 8. Embryos, E10.0: sections through prereacted whole-mounts labeled immunocytochemically and counterstained with toluidine blue. All panels illustrate that all axons are superficial, in the subpial zone. $a-d$ are all from the same embryo, oriented with rostral to the left. The planes of section are shown in Figure $5 a$. The opening on the caudal midline was not there in life; it was created surgically to facilitate penetration by the antibodies and other reagents. $a$, The cerebral vesicles $(c v)$ and ventricle $(v)$ are prominent. The labeled cells and axons are much more numerous caudally than rostrally; the cerebral vesicle has scarcely any at this level. The oculomotor nerve $(n I I I)$ is evident in the mesenchyme. The box labeled $b$ indicates the field shown in higher magnification in $b . b$, Labeled axons cut both transversely $(a, t)$ and longitudinally $(a, l)$ illustrate the superficial trajectory. $c$, The cerebral vesicle has a few more labeled cells at this level. The tract of the postoptic commissure $(t p o c)$ and the mammillotegmental tract $(m t t)$ are evident. $d$, The thick olfactory placode $(o p)$ contains labeled cells. The optic stalk $(o s)$, the neural retina $(r)$, and the lens placode $(l p)$ show the state of development of the eye. The trigeminal ganglion $(g V)$ and the descending tract of the mesencephalic nucleus of the trigeminal nerve (dtmes $V$ ) are indicated. $e$, This is a transverse section through the dorsal mesencephalon; the midline is just out of the field to the left. The skin $(s k)$ and ventricle $(v)$ are indicated. The labeled cells (the presumptive nmesV) are quite superficial, as are their axons, all of which course laterally (to the right). $f$, This is through the base of the optic stalk, oriented roughly orthogonally to Figure $4 b$. Rostral is up. The skin $(s k)$, mesenchyme $(m e)$, ventricle $(V)$, and midline $(m i)$ are indicated. Many of the cells in the anterobasal nuclei (abn) have reaction product in their ventricular processes. Labeled axons extend caudolaterally in the subpial zone. 
the few olfactory axons, no labeled processes originating outside of the cerebral vesicle were seen.

Summary. Figure 9 summarizes schematically the formation of the initial tracts in the mouse CNS. Three longitudinal tracts, one alar (dtmesV) and two basal (tpoc and mlf), were formed during the first $1.5 \mathrm{~d}$ of axon production. The vast majority, and perhaps all, of the early longitudinal axons were oriented caudally. Virtually all other central axons were initially oriented dorsoventrally and joined one of the three longitudinal tracts or crossed the midline ventrally.

\section{Discussion}

\section{The first axons?}

The birthdating studies of Taber Pierce (1973) and McConnell (1981) support the claim that the axons in the dimesV and the mlf are the first ones in the mouse brain, because class III $\beta$-tubulin appeared at the same time that the first terminal mitoses were inferred to have occurred. In the neural plate, immunoreactivity appeared at E8.5, and the first axons in the dorsal mesencephalon appeared at E9.0, the same day that Taber Pierce reported nmes $V$ originated. This coincidence suggests that axons were elaborated very soon after the terminal mitosis. As McConnell (1981) emphasizes, however, the nmesV cells were not alonc in making their terminal mitoses at this early time. The others that did so-in the brainstem reticular formation and in the superior olivary nucleus-did not produce axons comparably early, so it is not safe to infer from the existence of an axon that the terminal mitosis occurred shortly before.

Does the immunoreactivity reveal all neurons and axons? Two lines of evidence suggest that the TuJl antibody labels nearly all axons. First, it labels adult brains uniformly, with no obviously spared populations of neuronal somata and axons (A. Frankfurter, unpublished results). Second, in murine teratomas that differentiate into neural-tube-like structures, the "neuroepithelial cells" are labeled by this antibody (Caccamo et al., 1989a,b). Can the absence of a TuJ 1-labeled axon in a particular region be taken to imply that no axon exists there? This cannot be answered definitively, so caution must prevail and the possibility of false negatives cannot be excluded.

The alar plate axogenesis, extending through the prosencephalon, mesencephalon, and rhombencephalon (Figs. 3, 4), is quite precocious. This is a notable difference between the mouse and the other vertebrates that have been investigated at comparable stages: zebrafish (Chitnis and Kuwada, 1990; Wilson et al., 1990; Ross et al., 1992), Xenopus (J. S. H. Taylor and S. S. Easter, Jr., unpublished observations), and chick (S. S. Easter, Jr., unpublished observations).

\section{Restricted locations of the first axons}

The observation that all the early axons occupied the very superficial subpial zone conforms with published observations of other species (His, 1904; Marin-Padilla, 1971; Kevetter and Lasek, 1982; Easter and Taylor, 1989; Wilson et al., 1990; Wilson and Easter, 1991). In contrast, these axons and their somata are often very deep in the adult brain (see, e.g., the mlf, dtmesV, and the nucleus of the oculomotor nerve, in sections 360 and 361 of Sidman et al., 1971). Apparently the early cells and axons in the adult brainstem have been secondarily submerged by the addition of later ones, in an "inside-out" pattern of growth that was first demonstrated for the cerebral cortex.

The empirical generalization that early tracts form superfi-

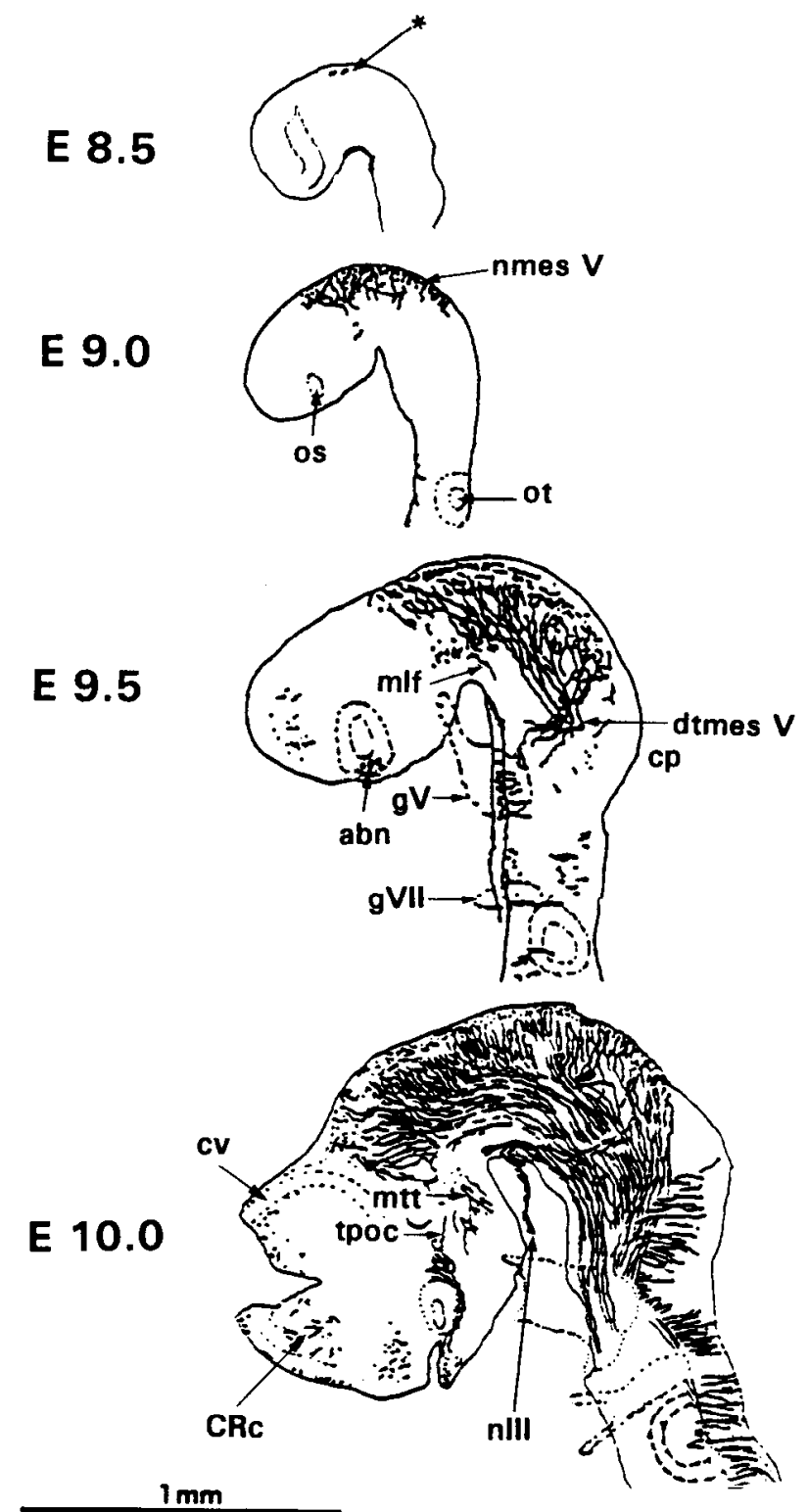

Figure 9. A schematic view of representative embryos of the four ages examined here. The scale bar applies to all four. In the E8.5 embryo, the asterisk indicates the first immunoreactive cells. In the other three embryos, particular structures are indicated when they first appear, but are left unlabeled in the latcr cxamples. $a b n$, antcrobasal nucleus; $c p$, cerebellar plate; $c v$, cerebral vesicle; $C R c$, Cajal-Retzius cells; dtmes $V$, descending tract of the mesencephalic nucleus of the trigeminal nerve; $g V^{\prime}$, ganglion of the trigeminal nerve; $g V I I$, ganglion of the facial nerve; $m l f$, medial longitudinal fasciculus; $m t t$, mammillotegmental tract; $n$ mes $V$, mesencephalic nucleus of the trigeminal nerve; $n I I I$, oculomotor nerve; os, optic stalk; ot, otocyst; tpoc, tract of the postoptic commissure. The scale bar applies to all panels.

cially, among the pial neuroepithelial end-feet, is unexplained, but features of this region offer possible clues to this mystery. According to the "blueprint hypothesis," preformed channels appeared there and provided avenues of low resistance to growth (Singer et al., 1979; Silver and Sidman, 1980). Cell adhesion molecules (Silver and Rutishauser, 1984) and substrate adhesion molecules (Letourneau et al., 1988) are concentrated there, and may provide an adhesive substrate. Glial fibrillary acidic protein appears there first in zebrafish embryos (Marcus and Easter, 
1990); it may stiffen the end-feet to provide a rigid substrate that growth cones can pull as they advance. These are naive suggestions concerning a part of the neural tube that is inadequately understood. When the subpial lamina is more completely described, some unique feature or set of features may emerge as the probable explanation. The only tract that has definitively been shown to be pioneered deep to this layer is the mammalian internal capsule, between cortex and thalamus (McConnell et al., 1989). It is tempting to suppose that it will show some of the features normally associated with the subpial zone, and these may provide the key to the puzzle.

Another possible restriction of early axons was noted by Lumsden and Keynes (1989; chick) and Trevarrow et al. (1990; zebrafish). They reported that during early axogenesis in the hindbrain, the first dorsoventral axons are restricted to interneuromeric boundaries. This finding was extended to the rostral part of the neural tube by Krauss et al. (1991), who found that the zones of expression of certain genes in the rostral zebrafish brain were outlined by the tracts known to exist there. These results both suggest that the neuromeres may be relatively inhospitable to axonal growth, and they raise the possibility that early dorsoventral tracts may all form in discrete bundles coincident with the boundary zones between neuromeres. Our illustrations of dtmesV (and those of Stainier and Gilbert, 1989) provide a clear exception to this generalization; in this case, the axons from a very broad region - perhaps the entire rostrocaudal extent of the dorsal mesencephalon and part of the synencephalon-appear to grow directly and relatively independently across the dorsal surface, and they form a unitary tract only when they approach the alar-basal boundary. Similarly, the alar plate axons from the synencephalon, parencephalon, and the cerebellar plate all grew more or less directly across their surfaces without coalescing into interneuromeric fascicles. The neuromeric centers are clearly not repulsive to axons.

\section{Previous descriptions of early development}

Development is hierarchically constrained, in the sense that late events depend on early ones. This is particularly important in the nervous system, which steadily increases in complexity over time; early events in CNS development are likely to be conserved with evolution (see Pettigrew, 1991, for a discussion of this point). In particular, once the stem organism that gave rise to vertebrates had developed a plan for the initial set of tracts, those animals that evolved from it would be expected to employ the same plan, and to add new structures and circuits later in development. This expectation can be evaluated, as the earliest tracts have now been described for members of three of the other four vertebrate classes - fishes, amphibians, and birds (but not reptiles).

Mammals. As was noted in the introductory remarks, early studies concluded that the mif was the first tract to appear in the rostral brain of mammals, but most failed to mention the tpoc, and none commented on the very early and massive projections from the alar plate. Tello (1934) studied mouse embryos 4-15 $\mathrm{mm}$ long. The time of gestation of the $4 \mathrm{~mm}$ embryos was not specified (not an uncommon omission in those days), but this is larger than our E9.0 embryos. We conclude that we have studied earlier stages than Tello, and we suggest that he failed to note the dtmes $\mathrm{V}$ because he examined stages so advanced that the two longitudinal tracts (dtmesV and mlf) were contiguous, as we have shown them to be by E10.0 (Fig. $5 a$ ). Windle's description of the $5.5 \mathrm{~mm}$ cat embryo, the smallest one with axons, includes mention of a tract tentatively identified as the dtmesV (Windle, 1932), but its origin could not be determined. Angulo y Gonzalez (1939) studied rat embryos, and commented specifically on the dtmesV, but found that it appeared after the mlf. Similarly, Rhines and Windle (1941), who studied the origin of the mlf in rat, cat, and human, suggest that it may be the first. We have no suggestion for why these earlier authors missed the nmesV and the dtmesV.

The tpoc was originally described in cmbryonic Ambystoma (Herrick, 1938), and was recently rediscovered in another amphibian, Xenopus laevis (Easter and Taylor, 1989), and zebrafish (Chitnis and Kuwada, 1990; Wilson et al., 1990). In the cat, it was probably included in the "supraoptic system" described by Windle (1935). We have no explanation for why Tello (1934) failed to see it in mice. Feng and Sretavan (1991) have examined the presumptive optic chiasm of mouse embryos slightly older than ours, and they describe a population of neurons arranged in an "inverted V-shaped band pointed anteriorly" and that extended their axons caudally in the direction of the future optic tract. The cell groups are almost certainly the abn, and the axons, the tpoc. They appear to play a role in the formation of the optic chiasm and tract. Their fate in the adult remains obscure; in rats, the cells in this nucleus are born over many days, and the earliest born may disappear before birth (S. A. Bayer, personal communication). This raises the possibility that the tpoc serves only a transient function in embryogenesis and then disappears, analogous to the cortical subplate neurons (Luskin and Shatz, 1985).

Mouse embryonic axonal development has been studied with other antibodies, as well. Those used by Stainier and Gilbert (1989, 1990, 1991) labeled trigeminal neurons early and selectively, and our results on dtmes $V$ and nmesV concur with theirs in all respects, including timing. Cochard and Paulin (1984) used anti-neurofilament antibodies, and the onset of label was at roughly the same time as we have described, but they made no attempt to assign the axons to tracts. Other immunolabeling studies of the development of the mouse CNS (Yamamoto et al., 1986; Edwards et al., 1989) have employed antibodies that begin to label later than ours, and have emphasized later development, and so are not directly comparable to ours.

The early human embryos studied by O'Rahilly and his collaborators over the last 20 years resemble the mice that we have described in more ways than space permits us to discuss, but a comparison of the schedules of development is instructive. O'Rahilly et al. (1984) have produced a sequence of the appearance of 100 characters over stages 7-13, which correspond roughly to E16-E33. Most of these characters (numbers 16-100), and all of those pertinent to the work in this article, occur over stages 13-15, or E28-E33. At stage 13, "loose cells appear in the chiasmatic plate" (which we take to be the formation of the abn), followed by formation of the "hypothalamic cell cord," a line of differentiated cells extending from the chiasmatic plate toward the cephalic flexure, and the mlf forms slightly later. At stage 14, the dtmesV appears, as do peripheral oculomotor fibers, and the "preoptico-hypothalamic tract" (our tpoc) begins to form along the substrate of the hypothalamic cell cord. At stage 15, the marginal layer of the cerebral vesicle is evident, the olfactory pit forms, and the Cajal-Retzius cells appear in the cerebral vesicle, concentrated in the area near the olfactory pit. These events, occupying about $3 \mathrm{~d}$ in humans, are quite 
similar to those that wc have described during $1 \mathrm{~d}$ in mice. The schedules differ slightly, in that the human mlf precedes the dtmesV (but maybe not, in view of the dtmes $V$ having been missed in other mammals).

Finally, our results argue against the claim of Marin-Padilla (1972) that the cerebral vesicle is invaded early by axons from outside and that these axons influence the development of the Cajal-Retzius cells. We have shown that Cajal-Retzius cells, early occupants of the superficial "primordial plexiform layer," are present by E10.0, but no labeled processes from outside had invaded this layer, or any other layer in the cerebral vesicle, at this time or $0.5 \mathrm{~d}$ later.

Birds. Tello (1923) and Windle and Austin (1935) used classical histological methods to investigate the formation of early tracts in the chick embryo. Both reports agree that the mlf is the first to develop, beginning with cells in the basal plate near the ccphalic flexure; both describe the tpoc, formed by caudally directed axons from cells near the optic stalk, and both note the $\mathrm{dtmesV}$, which appears a bit later. This is consistent with Covell and Noden (1989) and with our examination of the embryonic chick, using the same methods as in the present article (Easter, unpublished observations).

Amphibians. The embryonic brain of Xenopus laevis has recently been examined with most of the same methods that Wilson et al. (1990) used on zebrafish, and the two are very similar (Taylor and Easter, unpublished observations). Xenopus embryos from Nieuwkoop-Faber stages 25-34 resemble in detail zebrafish embryos 16-24 hr old (see below).

Fish. The first tracts in the brain of the zebrafish (Brachydanio rerio) have recently been described (Chitnis and Kuwada, 1990; Wilson et al., 1990). The tracts appear more rapidly in zebrafish, and the cells and axons are less numerous than in mouse or chick, but similarities abound. By $24 \mathrm{hr}$ of development, the presumptive fore and midbrain contain five tracts per side, two of which are ventral and longitudinal - the mlf and the tpocand they have clear homologs in the mouse. One of the other three, the tract of the posterior commissure, is probably included in the cluster of axons originating in the alar plate just rostral to the mesencephalon (Figs. $5 a, 9$ ). Homologs for the other two tracts in the zebrafish - the dorsoventral diencephalic tract and the supraoptic tract-are not readily identified in the mouse. Notably lacking in the zebrafish embryo, even at $48 \mathrm{hr}$, are nmesV and dtmesV (R. Marcus, unpublished observation). A dorsal longitudinal sensory tract (the lateral longitudinal fascicle) has been described in zebrafish (Metcalfe et al., 1986), but its rostralmost extent is at the entry of the trigeminal nerve into the hindbrain, so the dtmesV is missing. Teleost fish have a very reduced nmesV (Weinberg, 1928), and our failure to recognize it may be caused by either its small size or its late development. We conclude that two and perhaps three of the five tracts that appear first in the fish are recognizable in the amniotes, but the other two remain unidentified.

The patterns of development of the mlf, the tpoc, and the dorsoventral tributaries to each, are very similar in mice, chick, Xenopus, and zebrafish. The first axons in fish arise at $16 \mathrm{hr}$ from cells in the basal plate, at the rostrocaudal level of the cephalic flexure. They grow caudally to pioneer the mlf. These pioneer axons are joined by others from more caudal somata, and in only a few hours, the mlf extends from the cephalic flexure into the spinal cord. A few hours after this tract is initiated, axons grow caudally from cells at the base of the optic stalk to form the tpoc, and cells from the alar plate, dorsal to the cephalic flexure, send their axons along two distinct routes into these two longitudinal tracts (Ross et al., 1992).

Thus, the prediction that all early vertebrate brains should share a common set of tracts has been evaluated. Some differences were noted with respect to nmes $V$ and dtmesV, which were the first to form in mice, appeared later in chick, and were not observed in fish and Xenopus at the carly stages that have been examined. But the similarities between the representatives of the four vertebrate classes were even more striking, particularly with respect to the mif and the tpoc. These seemed to be clearly homologous, and to develop very precociously, in all. Most of the later axons, at least over the brief intervals examined here, seemed to be funneled into association with one of these preexisting tracts.

\section{A prediction}

The similarities of the early tracts in four vertebrate classes suggest that the prevertebrate stem organism must have had a similar pattern. In this connection, we recall the argument by Gans and Northcutt (1983) that the vertebrate head is probably an addition to, rather than an elaboration of, the most anterior end of the prochordate that gave rise to the vertebrate radiation. We suggest that the cells that give rise to the mlf are homologous to the most anterior neurons in the basal plate of this stem organism, and the part of the vertebrate brain that develops rostral to this is the new, uniquely vertebrate, part. If so, then the earliest cells to develop in embryonic prochordates of today, such as amphioxus (Branchiostoma), would be predicted to lie at the anterior pole of that animal's CNS, and to pioneer a ventral longitudinal tract. The study of initial tract formation in this animal should yield results that bear importantly on the evolution of the vertebrate CNS.

\section{References}

Altman J, Bayer SA (1986) The development of the rat hypothalamus. Adv Anat Embryol Cell Biol 100:1-178.

Angulo y Gonzalez AW (1939) Histogenesis of the monopolar neuroblast and the ventral longitudinal path in the albino rat. J Comp Neurol 71:325-360.

Caccamo D, Katsetos CD, Herman MN, Frankfurter A, Collins VP, Rubenstein LJ (1989a) Immunohistochemistry of a spontaneous murine ovarian teratoma with neuroepithelial differentiation: neuronassociated beta-tubulin as a marker for primitive neuroepithelium. Lab Invest 60:390-398.

Caccamo D, Katsetos CD, Frankfurter A, Collins VP, Vandenburg SR Herman MN (1989b) An immunohistochemical characterization of primitive and maturing neuroepithelial components in the OTT-6050 transplantable mouse teratoma. Neuropathol Appl Neurobiol 15: $389-405$.

Chan WY, Tam PPL (1988) A morphological and experimental study of the mesencephalic neural crest cells in the mousc cmbryo using wheat germ agglutinin-gold conjugate as the cell marker. Development 102:427-442.

Chitnis AB, Kuwada JY (1990) Axonogenesis in the brain of zebrafish embryos. J Neurosci 10:1892-1905.

Cochard P, Paulin D (1984) Initial expression of neurofilaments and vimentin in the central and peripheral nervous system of the mouse embryo in vivo. J Neurosci 4:2080-2094.

Covell DA Jr, Noden DM (1989) Embryonic development of the chick primary trigeminal sensory-motor complex. J Comp Neurol 286: $488-503$.

Dodd J, Morton SB, Karagugeos D, Yamamoto M, Jessell TM (1988) Spatial regulation of axonal glycoprotein expression on subsets of embryonic spinal neurons. Neuron 1:105-116.

Easter SS Jr, Taylor JSH (1989) The development of the Xenopus 
retinofugal pathway: optic fibers join a pre-existing tract. Development 107:553-573.

Edwards MA, Crandall JE, Wood JN, Tanaka H, Yamamoto M (1989) Early axonal differentiation in mouse CNS delineated by an antibody recognizing extracted neurofilaments. Dev Brain Res 49:185-204.

Eisen JS, Myers PZ, Westerfield M (1986) Pathway selection by growth cones of identified motoneurons in live zebrafish embryos. Nature 320:269-271.

Feng L, Sretavan DW (1991) A midline neuronal population is present at the mammalian optic chiasm during early retinal ganglion cell axon ingrowth. Soc Neurosci Abstr 17:182.

Gans C, Northcutt RG (1983) Neural crest and the origin of vertebrates: a new head. Science 220:268-274.

Glover JC, Petursdottir G (1991) Regional specificity of developing reticulospinal, vestibulospinal, and vestibulo-ocular projections in the chicken embryo. J Neurobiol 22:353-376.

Godement P, Vanselow J, Thanos S, Bonhoeffer F (1987) A study in developing visual systems with a new method of staining neurones and their processes in fixed tissue. Development 101:697-713.

Herrick CJ (1938) Development of the cerebrum of Amblystoma during the early swimming stages. J Comp Neurol 68:203-241.

His W (1904) Die Entwicklung des menschlechen Gehirns Wahrend der ersten Monate. Leipzig: Hirzel.

Honig MG, Hume RI (1986) Fluorescent carbocyanine dyes allow living neurons of identified origin to be studied in long-term cultures. J Cell Biol 103:171-187.

Kevetter GA, Lasek RJ (1982) Development of the marginal zone in the rhombencephalon of Xenopus laevis. Dev Brain Res 4:195-208.

Krauss S, Johansen T, Korzh V, Fjose A (1991) Expression pattern of zebrafish pax genes suggests a role in early brain regionalisation. Nature 353:267-270.

Kuwada JY (1986) Cell recognition by neuronal growth cones in a simple vertebrate embryo. Science 233:740-746.

Lee MK, Tuttle JB, Rebhun LI, Cleveland DW, Frankfurter A (1990a) The expression and postranslational modification of a neuron-specific beta tubulin isotype during chick embryogenesis. Cell Motil Cytoskel 17:118-132.

Lee MK, Rebhun LI, Frankfurter A (1990b) Posttranslational modification of class III beta-tubulin. Proc Natl Acad Sci USA 87: 7195-7199.

Letourneau PC, Madsen AM, Palm SL, Furcht LT (1988) Immunoreactivity for laminin in the developing ventral longitudinal pathway of the brain. Dev Biol 125:135-144.

Lumsden A, Keynes R (1989) Segmental patterns of neuronal development in the chick hindbrain. Nature 337:424-428.

Luskin MB, Shatz CJ (1985) Studies of the earliest generated cells of the cat's visual cortex: cogeneration of subplate and marginal zones. J Neurosci 5:1062-1075.

Marcus RC, Easter SS Jr (1990) Appearance and distribution of GFAP immunoreactivity in the embryonic zebrafish CNS. Soc Neurosci Abstr 16:310.

Marin-Padilla, M (1971) Early prenatal ontogenesis of the cerebral cortex (neocortex) of the cat (Felis domestica). A Golgi study. I. The primordial neocortical organization. Z Anat Entwicklungsgesch 134: $117-145$

Marin-Padilla M (1972) Prenatal ontogenetic history of the principal neurons of the ncocortex of the cat (Felis domestica). $\Lambda$ Golgi study. II. Developmental differences and their significances. $Z$ Anat Entwicklungsgesch 136:125-142.

McConnell JA (1981) Identification of early neurons in the brainstem and spinal cord. II. An autoradiographic study in the mouse. J Comp Neurol 200:273-288.

McConnell SK, Ghosh A, Shatz CJ (1989) Subplate neurons pioneer the first axon pathway from the cerebral cortex. Science 245:978-982.

Metcalfe WK, Mendelson B, Kimmel CB (1986) Segmental homologies among reticulospinal neurons in the hindbrain of the zebrafish larva. J Comp Neurol 251:147-159.

Moody SA, Quigg MS, Frankfurter A (1987) Development of the peripheral trigeminal system in the chick revealed by an isotypespecific anti-beta-tubulin monoclonal antibody. J Comp Neurol 279: $567-580$

O'Rahilly R, Muller F, Hutchins GM, Moore GW (1984) Computer ranking of the sequence of appearance of 100 features of the brain and related structures in staged human embryos during the first 5 weeks of development. Am J Anat 171:243-257.
Pettigrew JD (1991) Wings or brain? Convergent evolution in the origins of bats. Syst Zool 40:199-216.

Puelles L, Amat JA, Martinez-de-la-Torre M (1987) Segment-related, mosaic neurogenetic pattem in the forebrain and mesencephalon of early chick embryos: I. Topography of AChE-positive neuroblasts up to stage HH18. J Comp Neurol 266:247-268.

Rhines R, Windle WF (1941) The early development of the fasciculus longitudinalis medialis and associated secondary neurons in the rat, cat and man. J Comp Neurol 75:165-183.

Roberts A, Clarke JDW (1982) The neuroanatomy of an amphibian embryo spinal cord. Phil Trans R Soc Lond [Biol] 296:19-5-212

Ross LS, Easter SS Jr (1991) The first axons in the mouse CNS. Soc Neurosci Abstr 17:740.

Ross LS, Parrett T, Easter SS Jr (1992) Axonogenesis and morphogenesis in the embryonic zebrafish brain. J Neurosci 12:467-482.

Sidman RL, Angevine JB Jr, Taber Pierce E (1971) Atlas of the mouse brain and spinal cord. Cambridge, MA: Harvard UP.

Silver J, Rutishauser U (1984) Guidance of optic axons in vivo by a preformed adhesive pathway on neuroepithelial endfeet. Dev Biol 106:485-499.

Silver J, Sidman RL (1980) A mechanism for the guidance and topographic patterning of retinal ganglion cell axons. J Comp Neurol 189:101-111

Singer M, Nordlander RH, Egar M (1979) Axonal guidance during embryogenesis and regeneration in the spinal cord of the newt: the blueprint hypothesis of neuronal pathway patterning. J Comp Neurol 185:1-22.

Stainier DYR, Gilbert W (1989) The monoclonal antibody B30 recognizes a specific neuronal cell surface antigen in the developing mesencephalic trigeminal nucleus of the mouse. J Neurosci 9:2468-2485.

Stainier DYR, Gilbert W (1990) Pioneer neurons in the mouse trigeminal sensory system. Proc Nat Acad Sci USA 87:923-927.

Stainier DYR, Gilbert W (1991) Neuronal differentiation and maturation in the mouse trigeminal sensory system, in vivo and in vitro. $\mathrm{J}$ Comp Neurol 311:300-312.

Stallcup WB, Beasley LL, Levine JM (1985) Antibody against nerve growth factor-inducible large external (NILE) glycoprotein labels nerve fiber tracts in the developing rat nervous system. J Neurosci 5:1090-1101.

Sulston JE, Scierenberg E, White JG, Thomson JN (1983) The embryonic cell lineage of the nematode Caenorhabditis elegans. Dev Biol 100:64-119.

Svoboda KKH, O'Shea KS (1987) An analysis of cell shape and the neuroepithelial basal lamina during optic vesicle formation in the mouse embryo. Development 100:185-200.

Taber Pierce E (1973) Time of origin of neurons in the brain stem of the mouse. Prog Brain Res 40:53-65.

Tello JF (1923) Les differenciations neuronales dans l'embryon du poulet, pendant les premiers jours de l'incubation. Trab Rech Biol Univ Madrid 21:1-93.

Tello JF (1934) Les differenciations neurofibrillaires dans le prosencephale de la souris de 4 a 15 millimetres. Trab Rech Biol Univ Madrid 29:339-395.

Thomas JB, Bastiani MJ, Bate M, Goodman CS (1984) From grasshopper to Drosophila: a common plan for neuronal development. Nature 310:203-207.

Trevarrow B, Marks DL, Kimmel CB (1990) Organization of hindbrain segments in the zebrafish embryo. Neuron 4:669-679.

Weinberg E (1928) The mesencephalic root of the fifth nerve. A comparative anatomical study. J Comp Neurol 46:249-405.

Weisblat D (1988) Equivalence groups and regulative development. In: From message to mind: directions in developmental neurobiology (Easter SS, Barald KF, Carlson BM, eds), pp 209-223. Sunderland, MA: Sinauer.

Wilson SW, Easter SS Jr (1991) A pioneering growth cone in the embryonic zebrafish brain. Proc Natl Acad Sci USA 88:2293-2296.

Wilson SW, Ross LS, Parrett T, Easter SS Jr (1990) The development of a simple scaffold of axon tracts in the brain of the embryonic zebrafish, Brachydanio rerio. Development 108:121-145.

Windle WF (1932a) The neurofibrillar structure of the $7-\mathrm{mm}$ cat $\mathrm{em}$ bryo. J Comp Neurol 55:99-138.

Windle WF (1932b) The neurofibrillar structure of the $5.5 \mathrm{~mm}$ cat embryo. J Comp Neurol 55:315-331.

Windle WF (1935) Neurofibrillar development of cat embryos: extent 
of development in the telencephalon and diencephalon up to $15 \mathrm{~mm}$. J Comp Neurol 63:139-171.

Windle WF, Austin MF (1935) Neurofibrillar development in the central nervous system of chick embryos up to 5 days' incubation. J Comp Neurol 63:431-463.
Yamamoto M, Boyer AM, Crandall JE, Edwards M, Tanaka H (1986) Distribution of stage-specific neurite-associated proteins in the developing murine nervous system recognized by a monoclonal antibody. J Neurosci 6:3576-3594. 